\title{
Penile Schwannoma
}

National Cancer Institute

\section{Source}

National Cancer Institute. Penile Schwannoma. NCI Thesaurus. Code C162586.

A schwannoma that occurs in the penis. 